\title{
Networks of need: a geospatial analysis of secondary cities
}

\author{
Amanda Shores ${ }^{1}$, Hanna Johnson ${ }^{2}$, Debbie Fugate ${ }^{3}$ and Melinda Laituri ${ }^{1,2,4^{*}}$ (D)
}

\author{
*Correspondence: melinda.laituri@ \\ colostate.edu \\ ${ }^{1}$ Ecosystem Science and \\ Sustainability, Colorado State \\ University, Fort Collins, USA \\ ${ }^{2}$ Geospatial Centroid at CSU, \\ Colorado State University, Fort \\ Collins, USA \\ Full list of author information is \\ available at the end of the article
}

\begin{abstract}
Introduction: Urbanization and the continued growth of cities, both demographically and spatially, are topics of research studied across a range of disciplines in the urban millennium - a time in history when the majority of people live in cities. However, scholarly research has focused little attention on secondary cities, despite being the most rapidly growing cities in many low-and middle-income countries. Secondary cities, defined by their function rather than population size, are vital nodes for regional commerce and services. As these cities have historically been understudied, they lack geospatial data and the associated analyses important for local planners to understand how to meet current needs and plan for future growth. With this research, openly available geospatial data are evaluated, including both global (i.e., population distribution), local (i.e., municipal data), and data for four service categories (i.e., education, social, health, and food services). This research presents techniques to provide baseline understanding of data needs and accessibility of services in secondary cities with limited geospatial data and expertise.
\end{abstract}

Case description: We examine two secondary cities, Pokhara, Nepal, and Douala,

Cameroon. These cities are experiencing unplanned growth, development, and exposure to conditions that contribute to intra-urban inequalities. This research takes a spatial approach —coupling locally-created data sources (i.e., municipality data, fieldcollected, and non-governmental organizations' data) with global databases (i.e., world population and satellite images) to demonstrate how spatial data can be integrated and analyzed to enrich our limited understanding of secondary cities and the needs of resident populations. Four categories of services are evaluated and the distance to services from populated areas is calculated.

Discussion and evaluation: This research suggests that the distribution of services in both cities does not align with high-need, densely populated areas for certain services, a result of unplanned urban growth. Conversely, populations in areas far from the city center must travel relatively far distances to reach services, indicating lower levels of accessibility.

Conclusion: The results of this research serve to identify mapping needs and service accessibility. Projects focusing on geospatial data creation provide information needed for local populations to assess their community and the network of services offered. Additionally, local-decision makers can seek policy options to address unmet needs for community improvements and inequality reduction.

Keywords: Secondary cities, Urbanization, Population growth, Service accessibility, Distance-decay association, Spatial analysis, Douala, Cameroon, Pokhara, Nepal 


\section{Introduction}

Rapidly expanding in population and urban extent, secondary cities are centers of commerce, local governance, and social services (Marais et al. 2016, Roberts 2014, Rondinelli 1986). The total population size of secondary cities is not strictly defined, but in general they contain between 300,000 people (i.e., small city) to 1 million people (i.e., medium city) and are experiencing rapid population growth (Roberts 2014). Although they receive less attention than the 31 megacities around the world, $44 \%$ of the world's population live in small-to medium-sized cities whereas only $11 \%$ live in megacities (United Nations Department of Economic and Social Affairs 2016). While defined mainly by their function in a region, secondary cities often contain between 10 and $50 \%$ of the nation's largest city in either population or economy size (Roberts 2014; Marais et al. 2016). Secondary cities exist throughout the world but some of the fastest growing secondary cities are in low-and middle-income countries (Roberts 2014; United Nations Department of Economic and Social Affairs 2016). These cities are unique environments but due to rapid population growth, under development, and lack of local mapping and expertise in geospatial analyses, they have been poorly mapped and have limited information on population dynamics, infrastructure, and land tenure (Roberts 2014, Marais et al. 2016, McEvoy et al. 2014, Otiso 2005).

Geospatial data and analysis provide the foundation for long-term planning efforts to address citizen needs and access to basic resources (Yeh 1999). The complex and interacting nature of population growth, city expansion, access to city services, and decision-making practices make geospatial data and science-based planning vital for planned, sustainable growth (Mosha 1995). The Secondary Cities Initiative (2C) assists local partners in generating geospatial data, while also collecting existing global datasets and previously unavailable local administrative data (Laituri and Sternlieb 2016a). The $2 \mathrm{C}$ Initiative is a collaborative effort between the US Department of State Office of the Geographer, the American Association of Geographers, and Colorado State University. The $2 \mathrm{C}$ Initiative facilitates the generation of human geography data such as schools, health facilities, water access locations, and social services. Attributes of these data are collected providing description of the functions of city services. The development of a nascent global network of $2 \mathrm{C}$ partners facilitates the creation of new datasets and access to data previously not available. $2 \mathrm{C}$ data are housed on an open geodatabase platform, the $2 \mathrm{C}$ GeoNode, establishing a comprehensive dataset openly available for all city projects (Laituri and Sternlieb 2016b). One valuable lesson from informative service datasets is in understanding community needs for emergency preparedness and human security. An example is the mapping of recycling services throughout the city of Denpasar, Indonesia, where local communities recycle trash for a profit in neighborhood "trash banks" to fund improvement projects.

Secondary cities are often defined by their size, service, and function and provide services to the immediate region to improve quality of life (van der Merwe 2016). Services are generally concentrated in the inner city (within the administrative municipal boundary) but expansion of these urban areas into rural regions results in people residing within peri-urban extents (i.e., the urban periphery creating a transition zone to rural environments) (Allard 2004, Karg et al. 2019). If the addition of services does not align with built-up growth in the peri-urban extent, people in these areas may travel relatively far distances to access services. Identifying areas in and outside of the 
city with the most need for services can help better prepare for future growth (Allard 2004). Governments are responsible for providing services for their populations (i.e., through tax collection and central government funding). Peri-urban areas are often beyond the municipal boundary of cities and must rely on other entities to provide services, such as non-governmental organizations or other regional government agencies.

Spatial analyses of secondary cities are limited by the lack of geospatial data in these areas. Relatively simple analyses based on currently available geospatial data is the first step towards creating a baseline spatial description of secondary cities. One way to identify areas in need of additional services (as defined by the demand for a service based on population) is by examining the distance one must travel to reach needed services, demonstrating the spatial service accessibility (World Health Organization 2019). Research indicates that farther distances to services can be associated with a reduced quality of life (Wang 2018, Alvarez and Müller-Eie 2017, Manomano and Kang'ethe 2015). In the medical field, this is known as a "distance-decay association" which recognizes negative health outcomes the farther one resides away from health services (Frenkel and Israel 2018, Alvarez and Müller-Eie 2017). While this trend is not universally observed, the extent of this relationship has shown to be exacerbated by reduced access to transportation services (Kelly et al. 2016). People in secondary cities often walk as their primary mode of transportation, especially in low-and medium-development contexts, lending support to the existence of a distance-decay association regarding service accessibility in these cities (Olvera et al. 2015).

The distance to social, educational, and food services, while not as extensively studied as health services, can have a similar effect and disproportionately reduce the quality of life of those who reside relatively far from services (Allard 2004; Alvarez and MüllerEie 2017; Stock 1983; Manomano and Kang'ethe 2015). For example, students who live within walking distance from school are more likely to attend than those that live farther away (Filmer 2007). Since physical activity has been shown to increase academic achievement, living closer to schools can provide additional educational outcomes along with increased accessibility (Taras 2005). Other studies have shown that access to social resources can reduce the crime rate and increase community health and wellbeing (Kawachi et al. 1999, Manomano and Kang'ethe 2015, Blanford et al. 2012). Accessibility of services and the constraints one must overcome to utilize these resources, whether that be distance, transportation, or cost, can influence overall community wellbeing (Alvarez and Müller-Eie 2017; Stock 1983; Blanford et al. 2012). Providing baseline mapping of where services do not exist can assist city planners in identifying where to target resources in the future.

\section{Case description}

This research focuses on two Secondary Cities within the 2C Initiative: Pokhara, Nepal, and Douala, Cameroon. Due to the diversity of cities within the $2 \mathrm{C}$ Initiative, city partners collect data most relevant to their project as identified during a scoping assessment of data and city issues. The types of data collected are not uniform across $2 \mathrm{C}$ cities. Through preliminary evaluation of the types of data available for each of the $2 \mathrm{C}$ cities, Pokhara and Douala are shown to have the most comprehensive datasets available for a variety of similar service categories, allowing for cross-city comparison. The 
distribution and accessibility of services are evaluated in four service categories: health, social, educational, and food services. Attributes are not uniform across service categories, eliminating the ability to uniformly analyze attributes regarding the availability of services (i.e., service characteristics that include the ability to meet demand, and understand the characteristics of populations who utilize services) and the quality of services (i.e., how does the service meet a societal need of an individual). Point locations of different services allow for an assessment of the overall spatial accessibility of services (i.e., the distribution of services throughout an area) (World Health Organization 2019).

This research hypothesizes that there is a geographic correlation between densely populated areas and services in Pokhara and Douala, which demonstrates an ideal urban layout to meet the need of the most people in an area (Jackson 2003). A linear regression model utilizing the ordinary least squares tool in Esri ArcGIS Desktop 10.6 is conducted to evaluate whether densely populated areas correlate with relatively close distances to services, demonstrating alignment between need and service accessibility.

To provide a basic assessment of the demand for each service, service areas are created using the Thiessen polygon tool, which divides the area of interest into polygons where each polygon contains all areas closest to a particular service. Service areas within a category allows for examination of the relationship between the population that relies on a service and the distance they must travel to reach each service. Large service areas containing sizeable populations with residents that must travel far distances to reach the local service are considered to have low accessibility of services.

In addition to addressing need in densely populated areas, considering more remote and less densely populated areas within the peri-urban extent is also required to create equitable access to services and for future planning (Norström 2007; Karg et al. 2019). Many secondary cities have high rates of population growth that drive spatial expansion through territory annexation or settlement in adjacent, unoccupied peri-urban areas (Rusk 2006). As a part of the United Nations Sustainable Development Goal (SDG) 11, Sustainable Cities and Communities, an indicator was developed to access whether cities are consuming land (as determined by the amount of built-up area in a city) at a faster rate than population growth (SDGI 11.3.1). By calculating SDGI 11.3.1, secondary cities have been shown to experience more rapid spatial growth compared to population growth, particularly in the peri-urban extent, suggesting unsustainable development (Davis et al. 2019). For example, land consumption grew at a rate of at least 1.5 times the rate of population growth over 40 years in Denpasar, Indonesia, and Mekelle, Ethiopia, two cities in the $2 \mathrm{C}$ Initiative (Davis et al. 2019). The study area for this research explicitly focuses on the larger urban extent of the city, including the peri-urban areas, as representing the urban limit rather than the municipal boundaries (Norström 2007, Fonjong and Fokum 2017). Due to the variety of spatial layout, morphology, settlement, and needs of secondary cities, we consulted with local partners to define city extents.

\section{Douala, Cameroon}

Douala is the economic hub of Cameroon and the most populous city in the country (2.7 million) (African Development Bank 2015, Douala Urban Council 2011). It is located on the coast and contains intercoastal islands (Bele et al. 2011, Youssoufa et al. 
2011). The Wouri River forms a large estuary that divides the city (Bele et al. 2011, Youssoufa et al. 2011). Douala has grown rapidly since World War II and is one of the major industrial centers in central Africa (Douala Urban Council 2011). Douala's role as an economic hub is due to the location of Cameroon's major port (World Bank 2015). Between 1987 and 2012 the annual growth rate in Douala was 6.3\% and the population tripled between 2005 and 2017 (Mbonglou 2017; Douala Urban Council 2011). The United Nations projects the population will reach 4.774 million by 2030 while local experts expect Douala to grow to 5 million people by 2025 (United Nations Department of Economic and Social Affairs 2016, UN-DESA 2018). This rapid growth has put a strain on the weak infrastructure in Douala (Olvera et al. 2015).

Douala mirrors the general national characteristics of Cameroon that include infrastructure deficits, food insecurity, poor transportation, under-resourced education, and shortages of basic social and health services (World Justice Project 2013, Gorelick 2018, The World Bank 2018, Overseas Security Advisory Council 2019). Walking is the primary mode of transportation in the city, with those from lower socioeconomic status experiencing longer travel times and reduced number of trips (Olvera et al. 2015). One bridge connects the two sides of Douala across the Wouri River, which creates grid lock and dangerous conditions, especially for those walking (Olvera et al. 2015). High levels of maternal death $(0.6 \%)$ and child mortality $(3.1 \%)$ exist and HIV prevalence is higher than 10\% across Cameroon (UNICEF 2018; International Planned Parenthood Federation 2019). There are significant inequalities in access to food, with $16 \%$ of households reporting food insecurity throughout Cameroon (World Food Programme 2017). Douala is considered to have marginally better access to services compared to northern Cameroon. Douala's port provides essential goods and other commodities. Due to a lack of investment in upgrading the port, there can be long delays for delivery of goods causing an increase in food prices (Tchouawou 2015). The governance of Cameroon is highly centralized making it difficult for municipalities such as Douala to acquire localized municipal bonds to improve access to services and infrastructure (Gorelick 2018).

\section{Pokhara, Nepal}

Pokhara is located in the western region of Nepal and is the second most populated city in the country. The city is the Western Development Regional capital, one of seven new provincial capitals of Nepal (Aksha et al. 2019). Generally, information regarding services focus on Nepal rather than Pokhara specifically.

Nepal is one of the poorest countries in the world with inadequate infrastructure, facilities, and services (Poudel 2008; Rimal 2015). 45\% of the population fall below the poverty line (Parker 2013, The World Bank 2019). Nepalis experience food and economic insecurity, and low incomes (Rimal 2015; The World Bank 2019; Poudel 2008). The global hunger index rose from moderate to seriously insecure from 2009 to 2019 and $1 / 3$ of the population spends over $75 \%$ of their income on food (Pandey and Bardsley 2018, The World Bank 2019). 60\% of the population lacks access to basic health services (Mahato and Paudel 2015). The current state of education in Nepal is reportedly poor with literacy rates at $52 \%, 18 \%$ of primary age children not attending school, and overcrowded classrooms (World Bank 2014, Parker 2013). Poor teacher quality exists 
with only $1 / 3$ having received training. In addition, there are gender, caste, and regional disparities in access to education services (World Bank 2014, Parker 2013).

Nepal's problems are reflected to a lesser degree in Pokhara (Parker 2013). There are high rates of rural to urban migration and the population growth rate is $6.95 \%$ annually (Central Bureau of Statistics 2011). This population increase places additional pressure on the existing infrastructure (Central Bureau of Statistics 2011; Poudel 2008; Rimal 2015). The United Nations projects that the population will grow to 511,000 by 2025 (UN-DESA 2018). Due to its susceptibility to natural disasters and high population density, Western Nepal is considered one of the most disaster-prone regions in the world (Pokharel and Khanal 2018, Rimal et al. 2015). Informal settlements are found in hazardous areas such as the flood zone (Kaphle 2001). A study on the utilization of tertiary hospitals in Pokhara reveal that there are insufficient numbers of beds with high bed occupancy rates (over 70\%) (Mahato and Paudel 2015). People closest to these hospitals (generally found in more affluent neighborhoods) utilize the services more readily than those far away, implying a distance-decay association that infers a socioeconomic relationship to healthcare access (Mahato and Paudel 2015) (Fig. 1).

\section{Data}

Data were collected from the 2C GeoNode and OpenStreetMap (OSM). A comparison of data for each city found that social, health, educational, and food service data were available. To understand the extent of service accessibility in each city, service types were divided into four service categories (Table 1). The relevant $2 \mathrm{C}$ GeoNode and OSM data were combined, ensuring no repeat locations were included. Locally generated data, posted on the $2 \mathrm{C}$ GeoNode, possess a wealth of attributes describing specifics such as the service capacity and emergency preparation characteristics (i.e., access to water and backup generators). In this analysis, we combined 2C GeoNode and OSM data to increase the number of observations and assess overall spatial distribution of services. However, we were unable to address questions regarding service quality or capacity when data sources were combined as OSM data have fewer attributes. In addition, the underlying data structure of OSM attributes are not compatible with the data attribute format of the $2 \mathrm{C}$ GeoNode. WorldPop demographic data was utilized to understand the distribution of population density within each city (WorldPop 2015). Modeled and openly available administrative areas generated for the Global Administrative Areas Database (GADM) were downloaded for Douala and Pokhara through the DIVA-GIS platform (University of Berkeley, Museum of Vertebrate Zoology and the International Rice Research Institute 2012, Hijmans et al. 2001, University of Waterloo Geospatial Centre 2012).

\section{Methods}

\section{City and peri-urban extent}

The smallest administrative unit from the GADM administrative boundaries was used to define the $2 \mathrm{C}$ area of interest in this analysis. These city administrative boundaries were buffered to include the peri-urban extent. The GADM administrative boundary for Pokhara was smaller than the city extent so a buffer of $10 \mathrm{~km}$ was added to include 


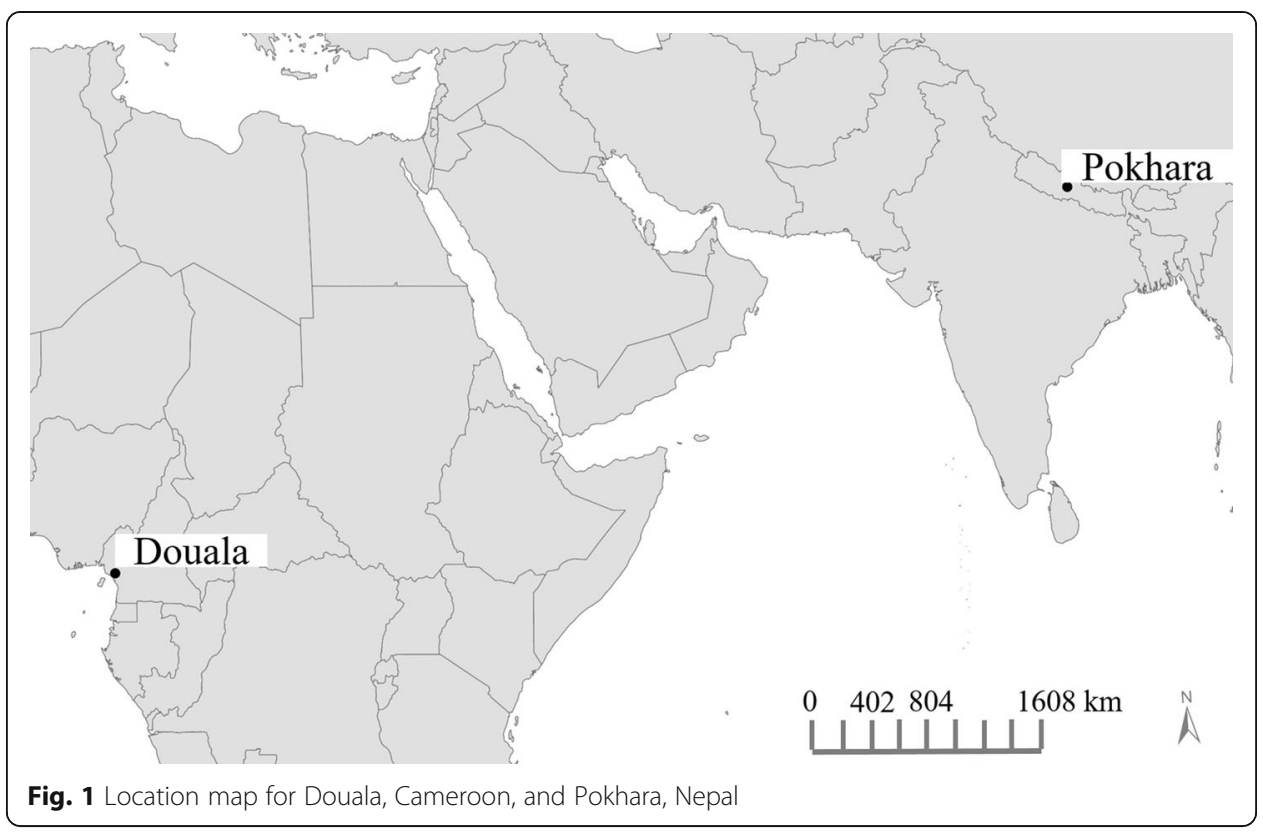

the peri-urban area. For Douala, the GADM administrative boundary corresponded with the city extent; a $2 \mathrm{~km}$ buffer was added to include the peri-urban extent.

\section{Distance to services}

People rarely travel as the crow flies (also known as Euclidean distance or geodesic distance). Roads are paths that make travel more efficient when utilizing a car or bike as compared to walking (Winters et al. 2010, Nesbitt et al. 2014). OSM road data were combined with $2 \mathrm{C}$ GeoNode road data for both Douala and Pokhara to apply a

Table 1 Data sources and service categories used in the study. Overlapping features representing the same location were eliminated. Two thousand one hundred fifty-six service features were included in the Pokhara case study, with 29\% from the 2 C GeoNode. Nine hundred ninety-four service features were included in the Douala case study, with $52 \%$ of features from the $2 \mathrm{C}$ GeoNode. "n/a" means there is no data available from a particular data source

\begin{tabular}{|c|c|c|c|c|c|}
\hline \multirow[t]{2}{*}{$\begin{array}{l}\text { Service } \\
\text { type } \\
\text { category }\end{array}$} & \multirow[t]{2}{*}{ Services within each category } & \multirow[t]{2}{*}{ City } & \multicolumn{2}{|c|}{$\begin{array}{l}\text { Number of } \\
\text { available points } \\
\text { from a } \\
\text { database }\end{array}$} & \multirow[t]{2}{*}{$\begin{array}{l}\text { Total } \\
\text { data } \\
\text { points }\end{array}$} \\
\hline & & & $\begin{array}{l}2 \mathrm{C} \\
\text { GeoNode }\end{array}$ & OSM & \\
\hline \multirow[t]{2}{*}{ Social } & \multirow{2}{*}{$\begin{array}{l}\text { Police Stations, Public Safety Assets, Embassies, Courthouse, } \\
\text { Social and Recreational Facilities, Parks, Monuments, Fountains, } \\
\text { Non-Governmental Organizations, Government Organizations, } \\
\text { Post Offices, Fire Stations, Libraries }\end{array}$} & Pokhara & 237 & 173 & 410 \\
\hline & & Douala & 11 & $\mathrm{n} / \mathrm{a}$ & 11 \\
\hline \multirow[t]{2}{*}{ Health } & \multirow[t]{2}{*}{ Hospitals, Pharmacies, Health Posts, Dentists, Clinics } & Pokhara & 303 & 219 & 522 \\
\hline & & Douala & 120 & 149 & 269 \\
\hline \multirow[t]{2}{*}{ Education } & \multirow[t]{2}{*}{ Schools (Any Level), Daycare } & Pokhara & 80 & 64 & 104 \\
\hline & & Douala & 383 & 241 & 624 \\
\hline \multirow[t]{2}{*}{ Food } & \multirow[t]{2}{*}{ Shopping Areas, Market Places, Supermarkets, Bakeries } & Pokhara & $\mathrm{n} / \mathrm{a}$ & 1120 & 1120 \\
\hline & & Douala & 5 & 85 & 90 \\
\hline
\end{tabular}


weighted cost distance model to calculate distance to services. However, these data layers had a variety of problems (i.e., incomplete road network, areas with no roads due to waterways). Similar observations were made when analyzing OSM road data for areas outside of urban centers (Quinn 2017). While a network analysis approach or a weighted cost distance model produces more accurate results for distance to services in highincome countries, studies in low-and middle-income countries show that using the Euclidean distance to services produce very similar results compared to other methods (Nesbitt et al. 2014). Due to these data limitations, the Euclidean tool in Esri ArcGIS 10.6 was selected as a proxy to provide a basic understanding of distance away from services (Nesbitt et al. 2014, Brabyn and Skelly 2002). This tool produces a raster layer that assigns the distance to the nearest point for each pixel, the distance of each pixel to a point is calculated "as the crow flies". The Euclidean tool utilizes the Pythagorean theorem to calculate distance away from a point. A resolution of $162 \mathrm{~m}^{2}$ for Pokhara and $305 \mathrm{~m}^{2}$ for Douala is used so that each raster contains roughly 65,000 pixels for each city.

The population density for a particular pixel was related to the Euclidean distance to travel to reach the nearest services in each category. To categorize these distances, a benchmark was established based on the longest distance to reach the nearest service out of any category and divided into thirds to create near, medium, and far distance ranges away from services (Table 2). Ordinary least squares (a linear regression model tool in Esri ArcGIS Desktop 10.6) was used to determine if the distance to services significantly correlate with population density (Fig. 2) (Francesca et al. 2018). All variables in the multiple linear regression model are continuous.

This linear regression model tests the following equation:

$$
\begin{aligned}
\text { Population Density }= & \text { Distance to Health Services } \\
& + \text { Distance to Social Services } \\
& + \text { Distance to Food Services } \\
& + \text { Distance to Educational Services. }
\end{aligned}
$$

The null hypothesis was rejected if the full linear model results in a $p$ value of $<0.05$, suggesting the distance to services is correlated with population density. The null hypothesis is rejected if a $p$ value of $<0.05$ is observed for each explanatory variable, suggesting the distances to a particular service is correlated with population density.

\section{Service area}

The Thiessen polygon tool (Esri ArcGIS 10.6) was used to geographically divide the city's features into "service areas" for each category (Fig. 2) (Brabyn and Skelly 2002; Twigg 1990). Because all locations in a Thiessen polygon are closest to a service point, they can be used to measure the distance to and the number of people dependent upon an individual service (Park 2012, Radke and Mu 2000, Gething et al. 2004). Three characteristics for each service area including total population, average Euclidean distance

Table 2 Classification of Euclidean distance to services. Ranges can only be compared between services within the specific city

\begin{tabular}{llll}
\hline City & Near range $(\mathrm{km})$ & Medium range $(\mathrm{km})$ & Far range $(\mathrm{km})$ \\
\hline Douala, Cameroon & $0-15.2$ & $15.21-30.3$ & $30.31-45.5$ \\
Pokhara, Nepal & $0-5.6$ & $5.61-11.3$ & $11.31-16.9$ \\
\hline
\end{tabular}




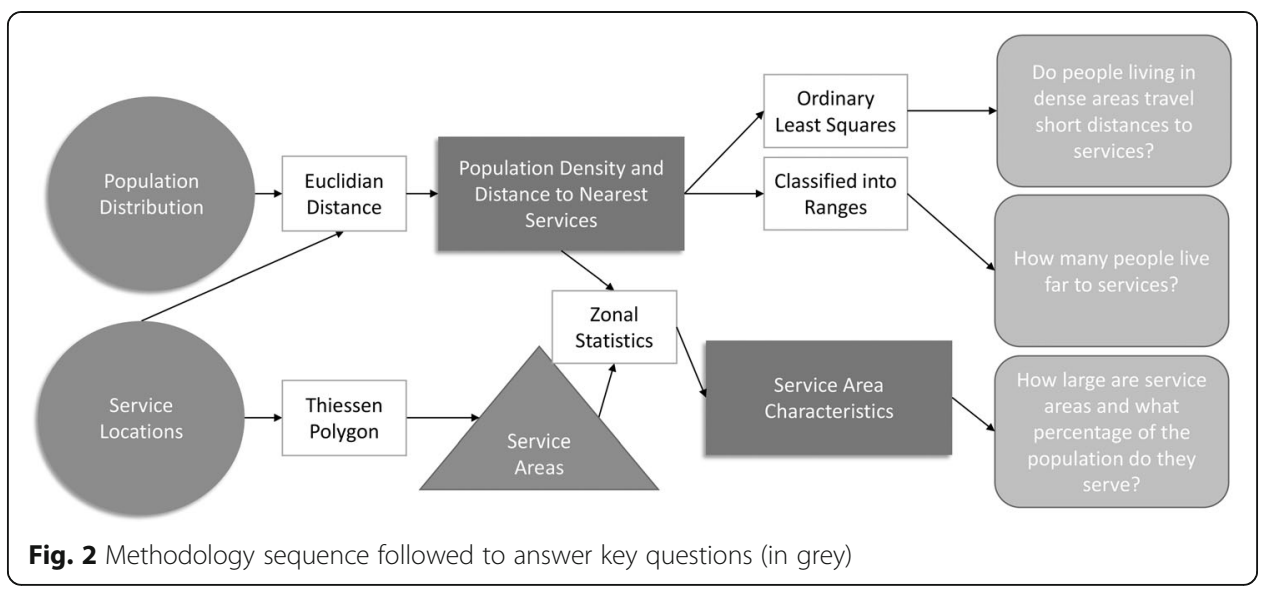

to the nearest service, and polygon area are calculated (Francesca et al. 2018). To decide which values delineate identified areas potentially lacking services, the maximum value obtained for a service area characteristic within a category was selected and divided into ranges of thirds, creating low, medium, and high ranges. Service areas that fell within the medium and high ranges for all three service area characteristics were deemed as identified areas lacking services (or availability of geospatial data). The service areas within a category were intersected to find areas that had overall inadequate access to all services examined (Fig. 2).

\section{Results}

When including peri-urban areas, the total area of the cities double in size. Without including surface water, the total area of Douala is $2173 \mathrm{~km}^{2}$ inclusive of the peri-urban extent. The city municipal boundary encompasses $43 \%$ of the $2 \mathrm{C}$ area of interest (Fig. 3). The majority of the 2 million inhabitants reside within the municipal boundary (92\%). Similarly, Pokhara's city boundary encompass $48 \%$ of the $2 \mathrm{C}$ area of interest including the city and peri-urban area. $82 \%$ of inhabitants live within the municipal boundary in Pokhara. Overall, the city extent for Douala has 2.4 times the land area and 4.2 times the population of Pokhara.

\section{Euclidean distance}

The Euclidean distance to services reveals that the farthest distance of a populated area to the nearest service is within the food service category and is $16.9 \mathrm{~km}$ for Pokhara and $45.5 \mathrm{~km}$ for Douala (Table 2).

Across all service categories, Douala contains the largest range of distances to services compared to Pokhara (Fig. 4). In Douala, the highest percentage of population is found at $305 \mathrm{~m}$ to the nearest educational service (29\% of the population), $305 \mathrm{~m}$ to the nearest food service ( $12 \%$ of the population), $305 \mathrm{~m}$ to the nearest health service (16\% of the population), and $1524 \mathrm{~m}$ to the nearest social service (4\% of the population). Comparing across services in Douala, higher percentages of people live near educational, food, and health services compared to social services. In Pokhara, the highest percentage of the population is found at $362 \mathrm{~m}$ to the nearest educational service (6\% of the population), $162 \mathrm{~m}$ to the nearest food service (21\% of the population), $162 \mathrm{~m}$ to 


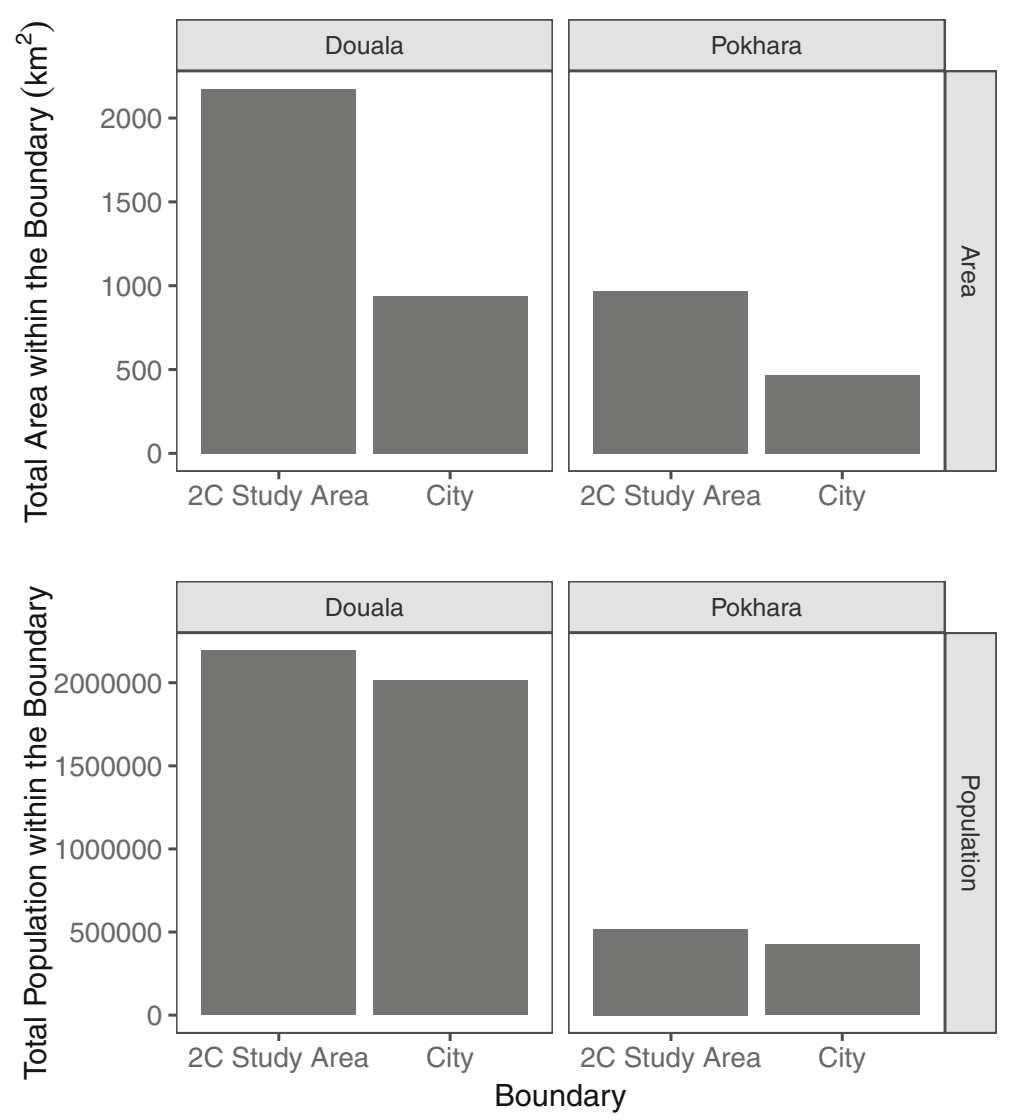

Fig. 3 General statistics for Douala and Pokhara. This graph depicts the area within the municipal boundary versus the $2 \mathrm{C}$ area of interest. Population totals within those two extents are shown

the nearest health service (17\% of the population), and $162 \mathrm{~m}$ to the nearest social service (17\%). For Pokhara, higher percentages of people live near food, health, and social services compared to education services (Fig. 4). While the overall range of distances to education services is shorter compared to other services, the highest percentage of the population from educational services is lower than for other services (Fig. 4). (Understanding what type of educational service is required to meet different age cohorts is an important aspect not evaluated in this study but is addressed in the Discussion and evaluation section.) Coincidentally, there is a lower number of education service features included in this study for Pokhara and a lower number of social service features for Douala compared to other services within the two study areas (Table 1).

Categorizing the population into ranges of distance to services shows the majority of people for both cities live relatively near to the four service categories (Fig. 5). Education services in Pokhara is the only category that has no individuals living in the range farthest to services.

\section{Correlation of population density and distance to services}

There is significant correlation between the distance to services and population density for both Douala (adjusted $R^{2}=0.105$, Joint Wald Statistic $p$ value $<1 \times 10^{-6}$ ) and 


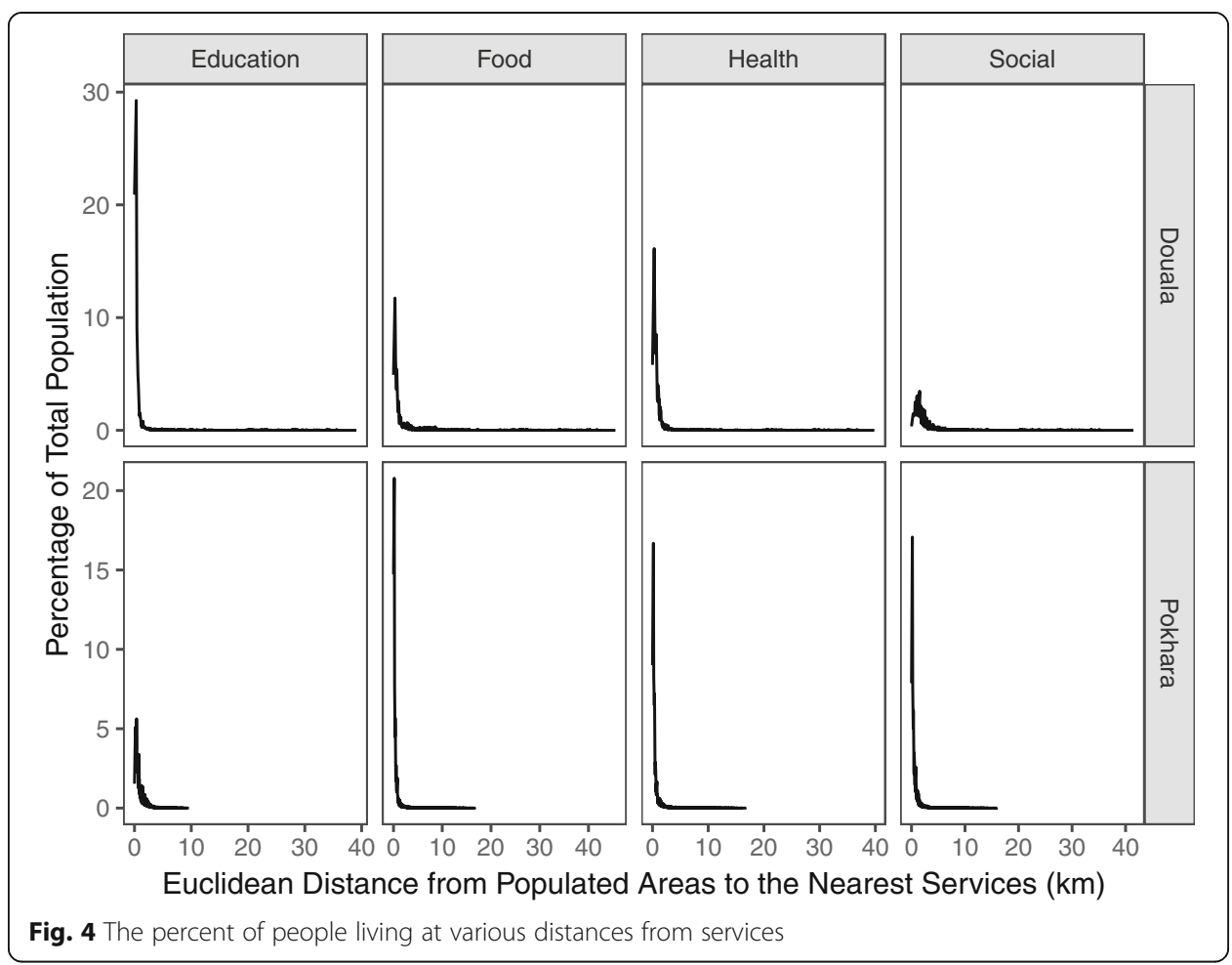

Pokhara (adjusted $R^{2}=0.118$, Joint Wald Statistic $p$ value $<2.2 \times 10^{-16}$ ) but the direction of the correlation is variable depending on the particular service category (Table 3 ). For Douala, shorter distances to food and social services significantly correlates with higher population densities but farther distances to educational and health services significantly correlates with higher population densities (Table 3). For Pokhara, shorter distances to educational, health, and food services significantly correlates with larger population densities; farther distances to social services significantly correlates to higher population densities (Table 3).

\section{Service areas and areas potentially lacking accessibility to services}

In Douala, the largest service area total identified as lacking service accessibility is in the food service category, which corresponds with the largest number of individuals in these areas (Table 4, Fig. 5). The smallest service area total identified as lacking service accessibility is the educational service category, which corresponds to the smallest number of individuals in these areas (Table 4, Fig. 5). There are no identified areas lacking services that intersect across all four service categories in Douala (Table 4). Across categories, the largest area contained within the Douala municipal boundary that are identified as lacking service accessibility is in food services, followed by the health services, social services, and educational services (Fig. 6).

In Pokhara, the largest total area identified as lacking service accessibility is in health services and the lowest total area is in social services (Table 4, Fig. 7). There is not a large difference in the total area identified as lacking services between categories for Pokhara (Table 4). The largest number of individuals in areas identified as lacking 


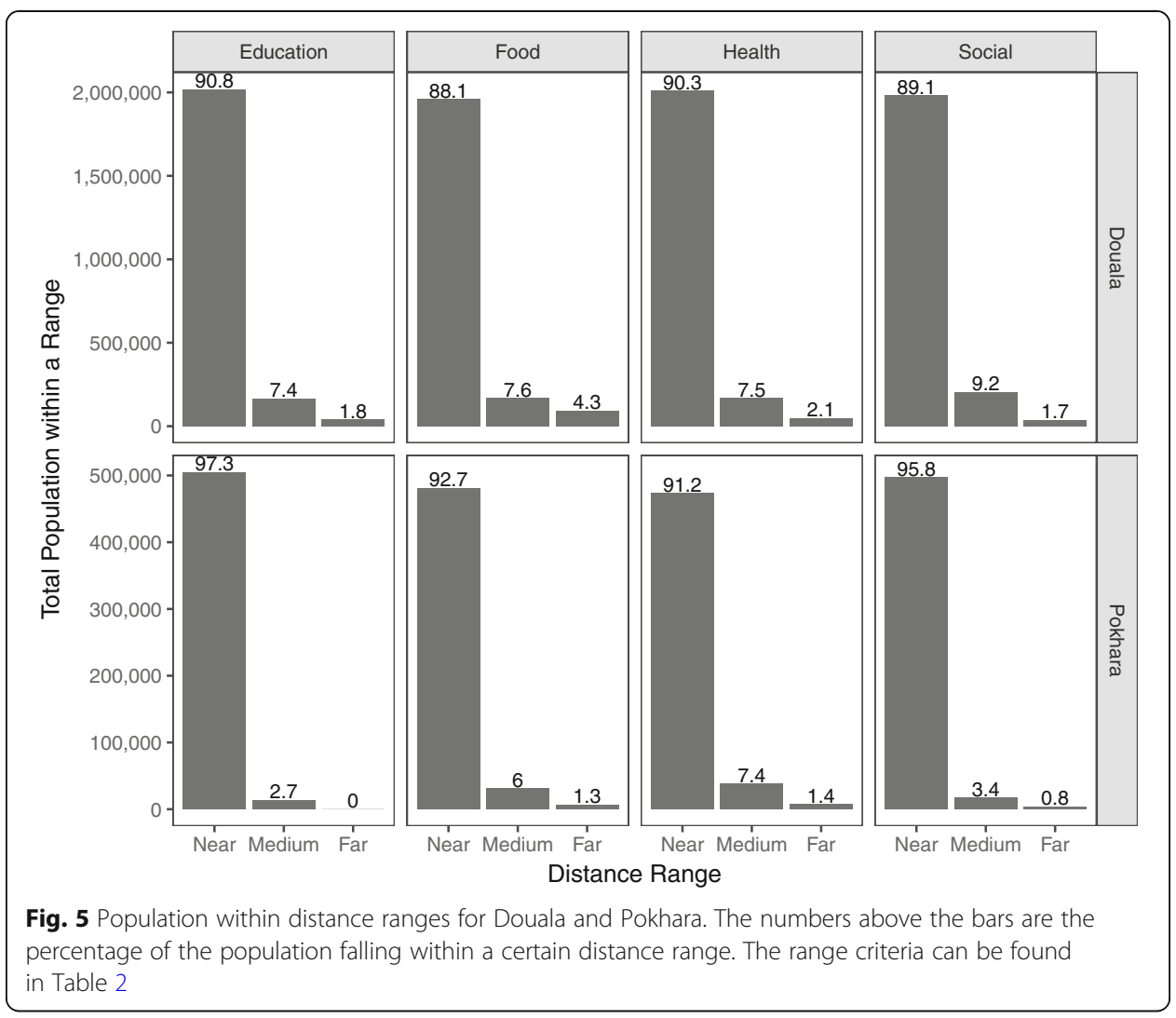

services is in health services and the smallest is in food services (Table 4, Fig. 7). Across service categories, the largest area contained within the Pokhara municipal boundary that is identified as lacking service accessibility is in health services, followed by educational services, food services, and social services (Table 4). An intersection of area that is identified as lacking services across all categories results in the identification of 94 $\mathrm{km}^{2}$ in the southwest portion of Pokhara. Twenty-three thousand eighty-five people reside within this area, encompassing $4.4 \%$ of the total population (Table 4, Fig. 8).

Table 3 Multiple linear regression results. Negative coefficients are interpreted as relatively shorter distances to a service correlating with higher density populations

\begin{tabular}{lllll}
\hline City & Explanatory variable & Coefficient & Standard deviation from the mean & Probability \\
\hline Douala & Intercept & 72.40 & 0.4828 & $<2 \times 10^{-16}$ \\
& Distance to Social Service $(\mathrm{m})$ & $-4.725 \times 10^{-3}$ & $5.967 \times 10^{-5}$ & $<2 \times 10^{-16}$ \\
& Distance to Health Service $(\mathrm{m})$ & $1.436 \times 10^{-3}$ & $1.256 \times 10^{-4}$ & $<2 \times 10^{-16}$ \\
& Distance to Education Service $(\mathrm{m})$ & $7.829 \times 10^{-3}$ & $1.173 \times 10^{-4}$ & $<2 \times 10^{-16}$ \\
& Distance to Food Service (m) & $-5.829 \times 10^{-3}$ & $7.574 \times 10^{-5}$ & $<2 \times 10^{-16}$ \\
Pokhara & Intercept & 9.974 & $5.405 \times 10^{-2}$ & $<2 \times 10^{-16}$ \\
& Distance to Social Service (m) & $7.348 \times 10^{-5}$ & $2.199 \times 10^{-5}$ & $8.34 \times 10^{-4}$ \\
& Distance to Health Service (m) & $-4.663 \times 10^{-4}$ & $2.236 \times 10^{-5}$ & $<2 \times 10^{-16}$ \\
& Distance to Education Service (m) & $-1.195 \times 10^{-3}$ & $1.975 \times 10^{-5}$ & $<2 \times 10^{-16}$ \\
Distance to Food Service (m) & $-1.843 \times 10^{-4}$ & $1.917 \times 10^{-5}$ & $<2 \times 10^{-16}$ \\
\hline
\end{tabular}


Table 4 Areas identified as potentially lacking service accessibility (Refer to Figs. 6, 7 and 8)

\begin{tabular}{lllll}
\hline City & $\begin{array}{l}\text { Service } \\
\text { category }\end{array}$ & $\begin{array}{l}\text { Identified area } \\
\text { potentially lacking } \\
\text { services }\left(\mathrm{km}^{2}\right)\end{array}$ & $\begin{array}{l}\text { Population in identified } \\
\text { area (percent of total } \\
\text { population) }\end{array}$ & $\begin{array}{l}\text { Intersecting areas lacking service } \\
\text { accessibility in all four service } \\
\text { categories }\left(\mathrm{km}^{2}\right)\end{array}$ \\
\hline Douala & Education & 358 & $123,185(5.54)$ & 0 \\
& Food & 1089 & $1,022,803(46.0)$ & \\
& Health & 942 & $432,307(19.4)$ & \\
& Social & 559 & $838,405(37.7)$ & \\
Pokhara & Education & 293 & $62,986(12.1)$ & \\
& Food & 237 & $38,800(7.48)$ & \\
& Health & 393 & $87,261(16.8)$ & \\
& Social & 218 & $52,874(10.2)$ & \\
\hline
\end{tabular}

\section{Discussion and evaluation}

The distance to services explain some of the population density variance within each city $\left(<12 \%\right.$ adjusted $\left.R^{2}\right)$, although the correlation is highly significant. This is not surprising as many other factors contribute to why people live where they do (i.e., environmental factors, kinship networks, and cost) (Thomas et al. 2015). The direction of this relationship where some service categories correlate with longer distances to densely populated areas, indicates a mismatch of service locations and need (Kelly et al. 2016, Guan et al. 2018, Blanford et al. 2012).

\section{Douala}

Shorter distances to educational and health services in Douala do not correlate with higher population densities. This suggests that these services are not as difficult for people to access in sparsely populated, rural areas compared to other services. This may be beneficial considering that the majority of lower socioeconomic status residents of Douala walk to reach a destination and take on average one trip a day (Olvera et al. 2015).

Education services have the smallest total area identified as potentially lacking service accessibility. The educational services are more evenly spatially distributed throughout the populated areas, allowing for shorter distances to this service, but providing less accessibility to more densely populated areas. Densely populated areas may have unmet educational needs because these services are not clustered. With overcrowded classrooms in Cameroon, these results suggest that educational services in the historical center of the city might be suffering from large classroom sizes (Hali Access Network 2016). We suggest conducting an evaluation on student accessibility to schools inclusive of classroom size, number of teachers, and type of facilities.

There are large areas lacking accessibility to food and health services within both the $2 \mathrm{C}$ area of interest and the municipal boundary. Food and health services are not well distributed within the more densely populated areas. Food services are clustered in the northern portion of the municipal boundary, suggesting that data collection for this service may be incomplete throughout the rest of the city. In consultation with $2 \mathrm{C}$ Douala partners, the lack of geospatial data for informal food services and social services is acknowledged where informal food establishments are one of the main ways to procure food. Increasing data collection for social services and food services is needed for future research. 


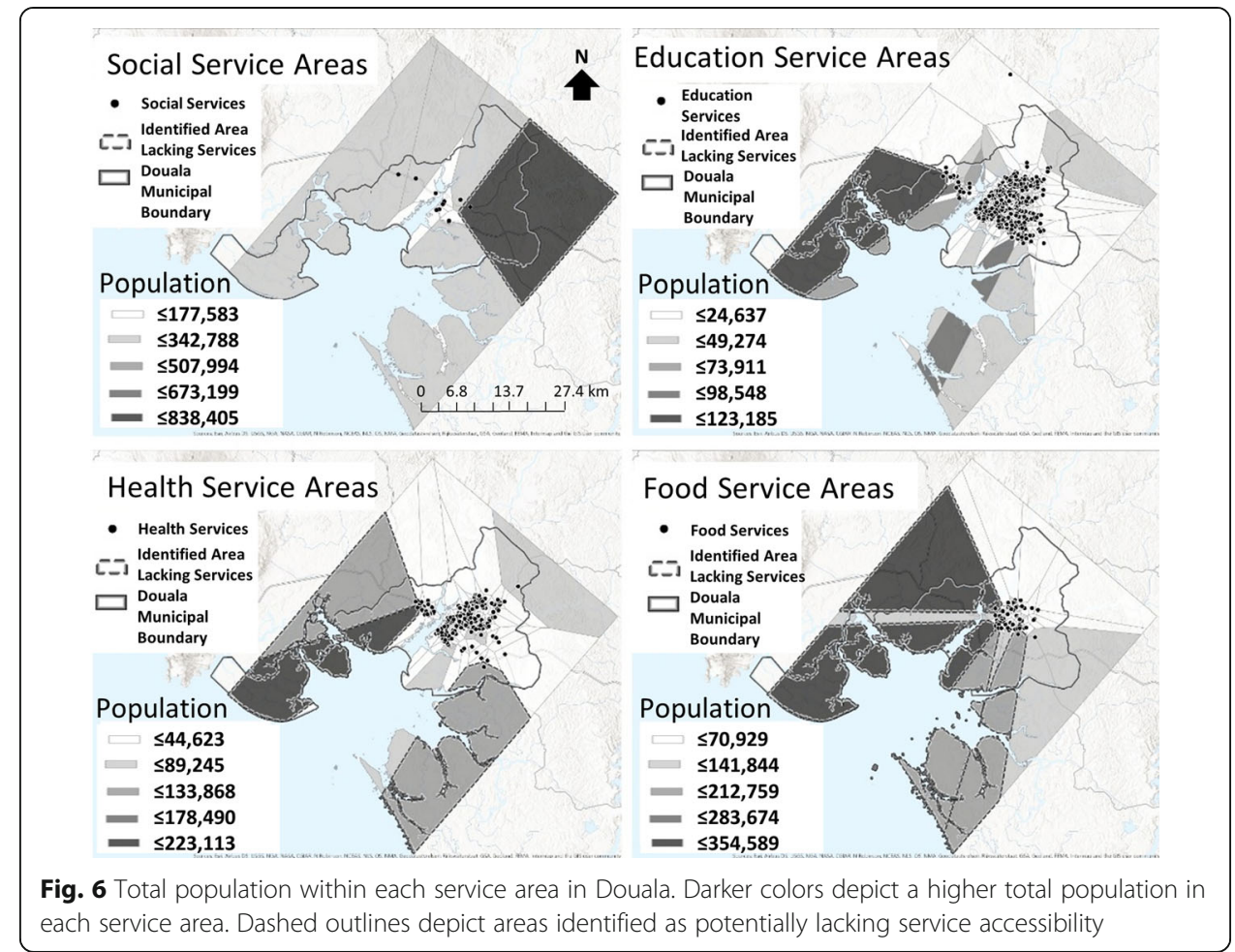

No areas are identified that lack all four services in Douala. However, 2C Douala partners confirm there is a wide disparity in the accessibility of services in the southern region of Douala compared to the north. The mangrove area in the southern region of Douala district IV is inhabited mainly by older mangrove loggers (Chretien et al. 2009, Fonteh et al. 2016). Additional resources and services are needed in this area, but these are areas of high risk due to extreme weather events and sea-level rise (Youssoufa et al. 2011, Yengoh et al. 2017). A study by Fonteh et al. (2016) found that residents of these areas are less informed about the projected impacts from climate change (i.e., sea level rise) than individuals who live in the city center (Youssoufa et al. 2011). Rather than adding services, an examination of the costs and benefits of mitigation options, such as retrofitting housing, or relocation should be undertaken.

\section{Pokhara}

Health, food, and education services correlate with higher population densities, suggesting that these services are meeting need in areas of high density. Social services do not correlate with more densely populated areas. A closer evaluation of social services would elucidate whether services can be added to meet need in high density areas. Overall, relatively few educational services are accessible (or mapped) in Pokhara. Educational services are one of the largest total areas lacking service accessibility (third largest out of the four service categories). With the many education-related issues that exist in Nepal (i.e., access to schools, gender disparities), the results of this case study affirm accessibility issues in Pokhara (Dilas et al. 2018, Parker 2013, Adhikary 2005, The World Bank 2019). 


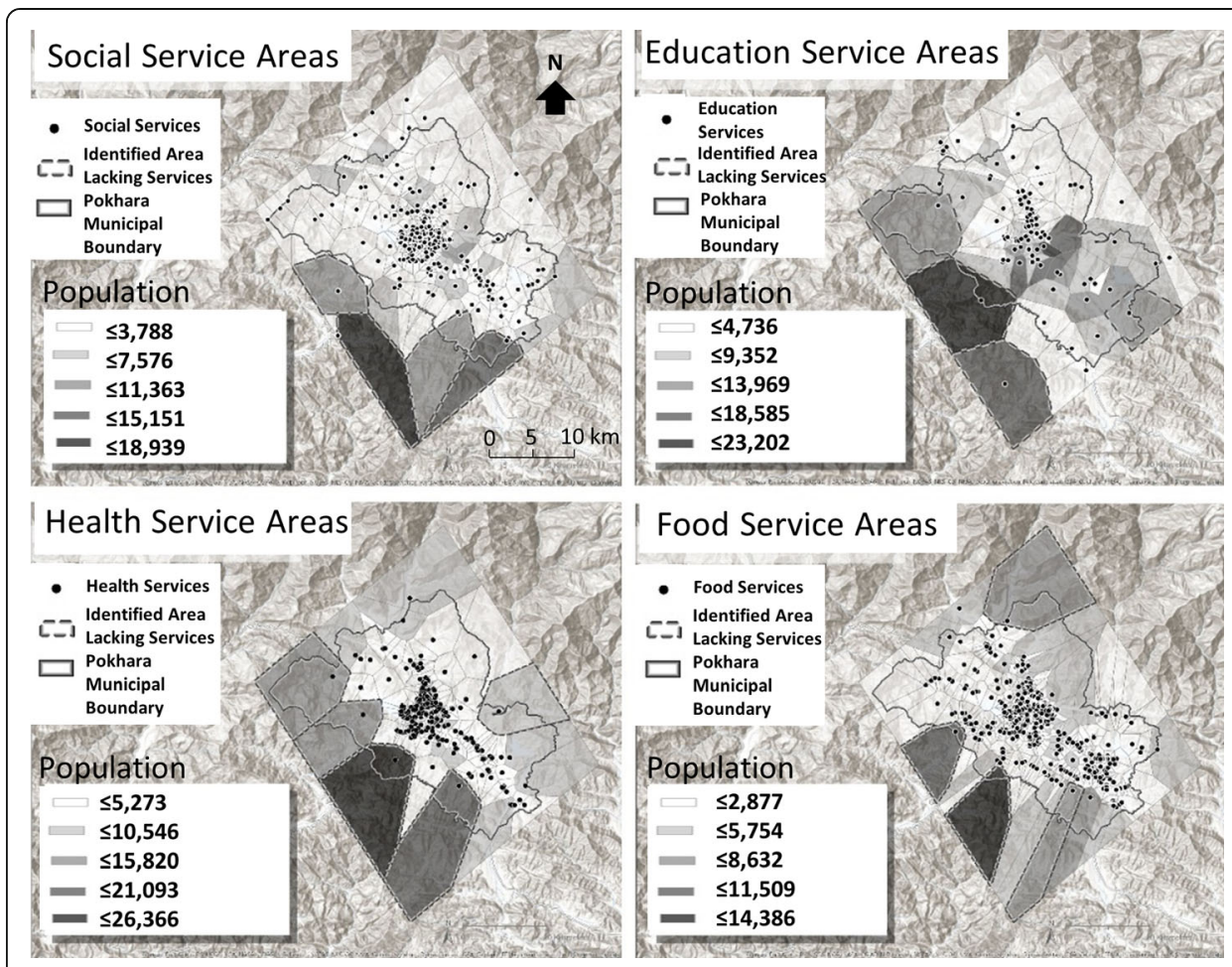

Fig. 7 Total population within each service area in Pokhara. Darker colors depict a higher total population in each service area. Dashed outlines depict areas identified as potentially lacking service accessibility

Intersection of areas that potentially lack service accessibility across categories are identified in the southwestern areas of Pokhara, suggesting these areas are the most vulnerable. Targeting these areas to improve access to services address the spatial disparity of services and would improve the quality of life for the most vulnerable (Alvarez and Müller-Eie 2017). Health and education categories have the first and second largest areas identified as lacking services, both within the $2 \mathrm{C}$ area of interest and the municipal boundary, and these areas represent the first and second largest proportion of the total population out of all categories, respectively. While it may be easier to secure funding for additional services within the city, targeting service areas that fall outside the city boundary and in the peri-urban extent may help plan for future growth.

Both Pokhara and Douala experience flooding, a common occurrence in the majority of 2C cities (Yengoh et al. 2017, Kaphle 2001; Laituri, pers.com.). Understanding where hazards occur identifies where vulnerable populations are located and helps pinpoint where and how resources should be allocated during hazard events. Analyses are needed to determine how and where to relocate individuals away from hazardous areas to areas with more service accessibility (Cernea 2000). The Secondary Cities Initiative maps and studies potential hazards and is the focus of upcoming analyses.

The methods used for this analysis are dependent upon a few assumptions and the results of this research should be interpreted with this understanding. Grouping all services into categories resulted in a larger, more comprehensive dataset that demonstrates the types of general services that are lacking and allows for comparison across services. However, the research does not weigh the individual impact of each service by 


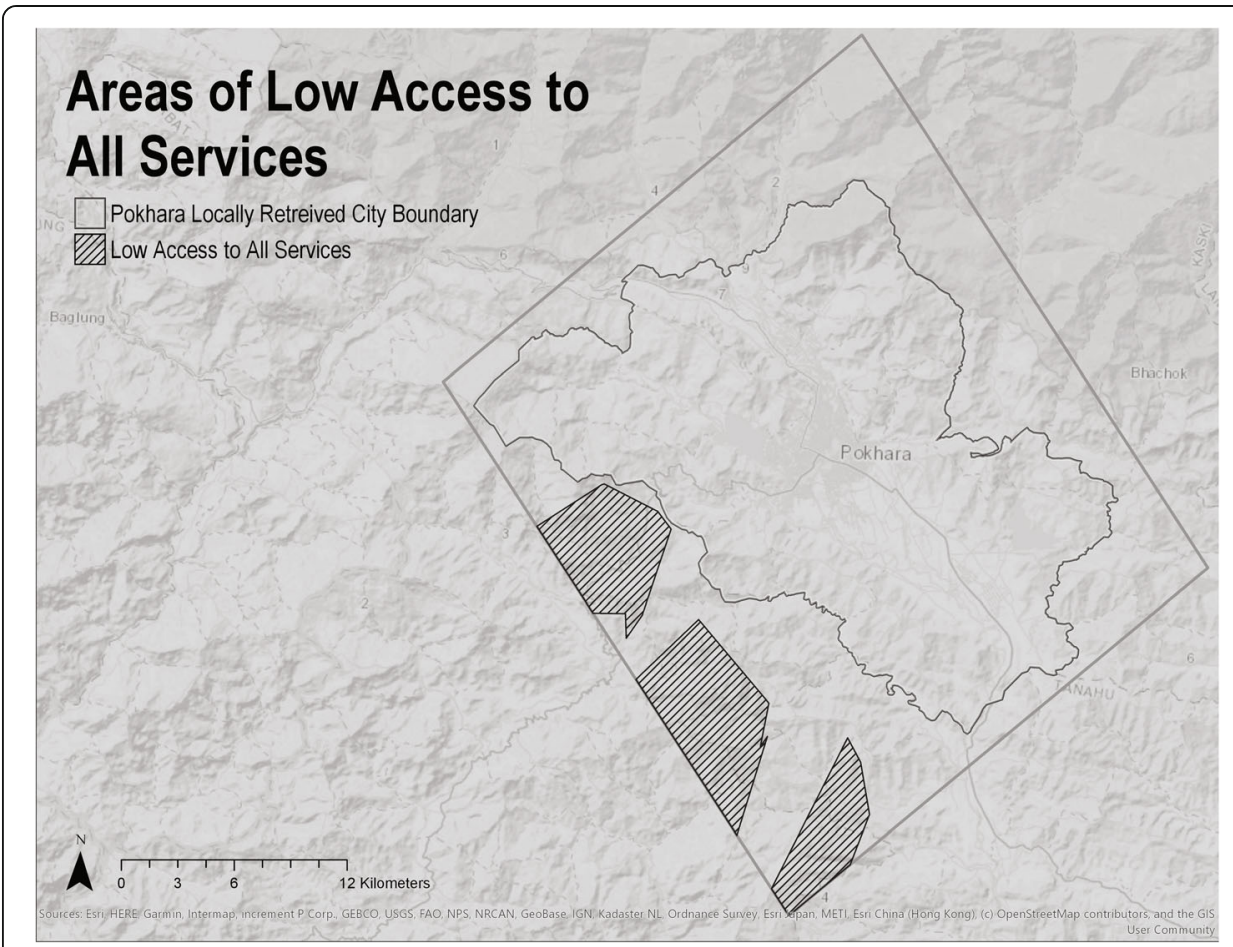

Fig. 8 Intersection of areas that lack accessibility of all services. Locally retrieved city boundary refers to the city municipal boundary

population demographics (Stock 1983). For example, the accessibility of a library might impact the community differently than living near a post office or police station. Similarly, living near a high school might not meet educational needs if students in the area need an elementary school.

The combination of data sources does not capture all services on the landscape. Local partners indicate data collected from Pokhara to be complete for all services. After the two earthquakes in Nepal in 2015, there is increased interest in mapping features using open source platforms such as OSM. OSM data complements the $2 \mathrm{C}$ Initiative data collection creating a more comprehensive dataset. Any missing data points can generate larger areas identified as lacking services. Douala lacks complete data on social and food services accessibility, revealing the dynamic need for ongoing data generation. Even with these limitations, our approach identifies service accessibility in areas that are under-mapped and under-studied. This research provides the methodology for $2 \mathrm{C}$ partners to continue data generation and analyses to assist city planners create a better understanding of their city.

\section{Conclusions}

Distance to services is one indicator that identifies areas that are lacking services. Other important factors include the quality, capacity, and availability of that service inclusive of demographic characteristics to provide a comprehensive geospatial analysis of service needs. Collecting additional information to enhance geospatial data within the city and peri-urban extent can be limited through the OSM platform due to the generic tagging nature of attributes (i.e., point features are located with limited information on point 
characteristics or attributes). A combined approach that allows for identifying service availability in the most densely populated areas and the rural peri-urban extent is critical to meet the needs of the most vulnerable. This research demonstrates a way to merge global and local datasets to understand potential areas of vulnerability within a community.

Information about what places actually are and what services they provide is difficult using remote sensing or remote mapping platforms (i.e., OSM). On-the-ground mapping teams are needed to survey service providers and the community to assess service utilization across demographics and locations. Through the $2 \mathrm{C}$ Initiative, we have learned that using local teams for survey development and mapping reduces biases and builds trust with local communities and decision makers.

The U.S. Department of State Secondary Cities Initiative and other city mapping projects (i.e., Smart Cities, Cities Alliance, EcoCityBuilders), understand the importance of locally-generated data that is openly available for analysis and interpretation to help rapidly-developing cities grow in a planned and sustainable manner. The Secondary Cities Initiative includes generating local data as well as gathering valuable details about these places that enhance our understanding of the needs of communities and planning for future growth. Essential to the Secondary Cities Initiative is the ability to analyze locally-generated data and validate the findings with our local partners. The Secondary Cities Initiative holds technical exchanges and webinars to assess the accuracy of our findings. In 2019, the results from our work were presented to our local partners during technical exchanges, the process and findings of which is the basis for further research and analysis. These activities build a network of geospatial practitioners around the world to assist decision makers to develop strategies for sustainable growth and development.

\section{Abbreviations}

2C: Secondary Cities; DIVA-GIS: Free computer program for mapping and analyzing spatial data; GADM: Global Administrative Area Database; GIS: Geographic information system; OSM: OpenStreetMap; SDG: Sustainable Development Goal; SDGl: Sustainable Development Goal Indicator

\section{Acknowledgements}

Secondary Cities (2C) is a field-based initiative of the Office of the Geographer at the U.S. Department of State that builds partnerships to enhance geospatial capacity, generate data, and share maps to support planning for sustainable and resilient cities. We acknowledge the many students, partners, and organizations who make this a successful initiative.

\section{Authors' contributions}

AS developed the method for data analysis, analyzed and interpreted the data, and wrote the manuscript. HJ created the maps. AS and ML provided oversight, methodological guidance, and editorial comments. ML is the principal investigator on the Secondary Cities Initiative. DF reviewed and commented on the paper. All authors read and approved the final manuscript.

Funding

The Secondary Cities Initiative is funded by the U.S. Department of State and the American Association of Geographers (AAG).

Availability of data and materials

The datasets generated and/or analyzed during the current study are available in the 2C GeoNode repository, [https:// secondarycities.geonode.state.gov/] and OpenStreetMap, 15 April 2019, [https://www.openstreetmap.org/\#map=4/38. 01/-95.84]. Additional analysis results are available from the corresponding author on reasonable request. 


\section{Author details}

${ }^{1}$ Ecosystem Science and Sustainability, Colorado State University, Fort Collins, USA. ${ }^{2}$ Geospatial Centroid at CSU, Colorado State University, Fort Collins, USA. ${ }^{3}$ Department of Geography, San Diego State University, San Diego, USA. ${ }^{4}$ US Department of State, Office of the Geographer and Global Issues, Washington, DC, USA.

\section{Received: 22 May 2019 Accepted: 25 October 2019}

Published online: 21 November 2019

\section{References}

Aksha SK, Juran L, Resler LM, Zhang Y (2019) An analysis of social vulnerability to natural hazards in Nepal using a modified social vulnerability index. Int J Disaster Risk Sci 10:103-116. https://doi.org/10.1007/s13753-018-0192-7 Accessed 3 Mar 2019

Allard SW (2004) Access to social services: the changing urban geography of poverty and service provision. The Brookings Institute, Washington, DC, pp 1-19 Accessed 22 Mar 2019

Alvarez AL, Müller-Eie D (2017) Quality of urban life and its relationship to spatial conditions, Seville. WIT Trans Ecol Envir. 223: 285-296.

Blanford Jl, Kumar S, Luo W, MacEachren AM (2012) It's a long, long walk: accessibility to hospitals, maternity and integrated health centers in Niger. Int J Health Geogr 11(24):1-15. https://doi.org/10.1186/1476-072X-11-24 Accessed 30 Mar 2019

Brabyn L, Skelly C (2002) Modeling population access to New Zealand public hospitals. Int J Health Geogr 1:1-9

Central Bureau of Statistics (2011) Census info Nepal 2011. Government of Nepal. http://dataforall.org/dashboard/ nepalcensus/. Accessed 22 Aug 2019

Cernea MM (2000) Risks, safeguards and reconstruction: a model for population displacement and resettlement. Econ Polit Wkly 35:3659-3678 Accessed 29 Mar 2019

Chretien N, Tiafack O, Charly DNG (2009) Mapping and monitoring urban growth on wetlands in humid tropical context using earth observation technology: case study of mangrove zones around Douala in Cameroon. In: 2009 IEEE international geoscience and remote sensing symposium, pp 120-123 Accessed 3 Mar 2019

Davis D, Sternlieb F, and Laituri M (2019) Assessing sustainable development goal indicator 11.3.1: land consumption for inclusive and sustainable urban growth in secondary cities. Manuscript in Preparation, Colorado State University

Dilas D B, Cui J, Trines S (2018) Education in nepal. World education news and reviews. https://wenr.wes.org/2018/04/ education-in-nepal. Accessed 30 Aug 2019

Douala Urban Council (2011) Plan directeur d'urbanisme de Douala a I'horizon 2025

Filmer D (2007) If you build it, will they come? School availability and school enrolment in 21 poor countries. J Dev Stud 43: 901-928. https://doi.org/10.1080/00220380701384588 Accessed 10 Mar 2019

Fonjong L, Fokum V (2017) Water crisis and options for effective water provision in urban and peri-urban areas in Cameroon. Soc Nat Resour 30:488-505. https://doi.org/10.1080/08941920.2016.1273414 Accessed 13 Mar 2019

Fonteh L, Théophile M, Lambi F, Cornelius M (2016) Stakeholder perception of global warming, rainfall variability and sea level rise hazard perils in three coastal districts of Douala-Cameroon. Environ Earth Sci 6:115-131 Accessed 8 May 2019

Francesca M, Zambon I, Salvati L (2018) Population matters: Identifying metropolitan sub-centers from diachronic densitydistance curves, 1960-2010. Sustainability 10(4653):1-16

Gething PW, Noor AM, Zurovac D (2004) Empirical modelling of government health service use by children with fevers in Kenya. Acta Trop 91:227-237. https://doi.org/10.1016/j.actatropica.2004.05.002

Gorelick J (2018) Supporting the future of municipal bonds in sub-Saharan Africa: the centrality of enabling environments and regulatory frameworks. Environ Urban 30(1):103-122 https://doi.org/10.1177/0956247817741853. Accessed 2 Sept 2019

Guan X, Wei H, Lu S, Su H (2018) Mismatch distribution of population and industry in China: pattern, problems and driving factors. Appl Geogr 97:61-74. https://doi.org/10.1016/j.apgeog.2018.05.021 Accessed 25 Mar 2019

Hijmans RJ, Guarino L, Cruz M, Rojas E (2001) Computer tools for spatial analysis of plant genetic resources data: 1. Diva-GIS. Plant Genet Resour Newsl 127:15-19

International Planned Parenthood Federation (2019) Cameroon National Association for Family Welfare. https://www.ippf.org/ about-us/member-associations/cameroon. Accessed 2 Sept 2019

Jackson LE (2003) The relationship of urban design to human health and condition. Landsc Urban Pln 64:191-200. https:// doi.org/10.1016/S0169-2046(02)00230-X Accessed 26 Feb 2019

Kaphle KP (2001) Natural hazards and environmental geological assessment of Pokhara Valley, Western Nepal. J Nepal Geol Soc 24:70-71. Accessed 3 Mar 2019

Karg H, Hologa R, Schlesinger J, Drescher A, Kranjac-Berisavljevic G, Glaser R (2019) Classifying and mapping peri-urban areas of rapidly growing medium-sized sub-Saharan African cities: a multi-method approach applied to Tamale, Ghana. Land $8(40) 1-22$.

Kawachi I, Kennedy BP, Wilkinson RG (1999) Crime: social disorganization and relative deprivation. Soc Sci Med 48:719-731. https://doi.org/10.1016/S0277-9536(98)00400-6 Accessed 2 Apr 2019

Kelly C, Hulme C, Farragher T, Clarke G (2016) Are differences in travel time or distance to healthcare for adults in global north countries associated with an impact on health outcomes? A systematic review. BMJ Open 6. https://doi.org/10. 1136/bmjopen-2016-013059 Accessed 10 Mar 2019

Laituri M, Sternlieb F (2016a) Secondary cities. In: Secondary cities http://secondarycities.state.gov/. Accessed 22 Mar 2018

Laituri M, Sternlieb F (2016b) Secondary cities GeoNode. In: Secondary cities GeoNode https://secondarycities.geonode.state. gov/. Accessed 14 May 2019

Mahato PK, Paudel GS (2015) Access to free health-care services for the poor in tertiary hospitals of western Nepal: a descriptive study. WHO South-East Asia J Public Health 4(2):167-175

Manomano T, Kang'ethe SM (2015) Exploring the extent to which the distance to centers of social services affects the quality of life of the RDP Residents: the case of 2013 RDP golf course study, Eastern Cape, South Africa. Hum Ecol 49:139-148. https://doi.org/10.1080/09709274.2015.11906832 Accessed 23 Mar 2019

Marais L, Nel E, Donaldson R (2016) Secondary cities and development. Routledge, Abingdon 
Mbonglou G (2017) Douala, Cameroon as a secondary city. Secondary city initiative

McEvoy D, Ahmed I, Trundle A (2014) In support of urban adaptation: a participatory assessment process for secondary cities in Vietnam and Bangladesh. Clim Dev 6:205-215. https://doi.org/10.1080/17565529.2014.886991

Merwe VD (2016) In search of an urbanization policy for South Africa: Towards a secondary city strategy. Geo Res Forum 12 $102-127$

Mosha AC (1995) A reappraisal of the urban planning process. UN-HABITAT

Nesbitt RC, Gabrysch S, Laub A et al (2014) Methods to measure potential spatial access to delivery care in low- and middleincome countries: a case study in rural Ghana. Int J Health Geogr 13:25. https://doi.org/10.1186/1476-072X-13-25 Accessed 18 Mar 2019

Norström A (2007) Planning for drinking water and sanitation in peri-urban areas: a proposed framework for strategic choices for sustainable living. Swedish Water House, Stockholm Accessed 20 Mar 2019

Olvera LD, Plat D, Pochet P (2015) Assessment of mobility inequalities and income data collection. Methodological issues and a case study (Douala, Cameroon). J Transp Geogr 46:180-188 https://doi.org/10.1016/j.trangeo.2015.06.020

Otiso KM (2005) Kenya's secondary cities growth strategy at a crossroads: which way forward? GeoJournal 62:117-128. https://doi.org/10.1007/s10708-005-8180-z

Overseas Security Advisory Council (2019) Cameroon 2019 crime and safety report. Bureau of Diplomatic Security, U.S. Department of State. https:/www.osac.gov/Country/Cameroon/Content/Detail/Report/b1678858-8009-43c5-9c7b-16 Deea6972d9. Accessed 2 Sept 2019

Pandey R, Bardsley D (2018) An application of household food insecurity access scale to assess food security in rural communities of Nepal. Asia Pac Policy Stud 6:130-150 https://doi.org/10.1002/app5.270

Park SJ (2012) Measuring public library accessibility: a case study using GIS. Libr Inf Sci Res 34:13-21. https://doi.org/10.1016/j. lisr.2011.07.007

Pokharel RP, Khanal NR (2018) Open space: typology and distribution in Pokhara Lekhnath metropolitan city. Geogr J Nepal 11:25-44

Poudel KR (2008) Urban growth and land use change in the Himalayan region: a case study of Pokhara Sub-Metropolitan City, Nepal. GIS Ostrava. https://www.researchgate.net/profile/Khagendra_Poudel2/publication/237269591_URBAN_ GROWTH_AND_LAND_USE_CHANGE_IN_THE_HIMALAYAN_REGION_A_CASE_STUDY_OF_POKHARA_SUBMETROPOLITAN_CITY_NEPAL/links/55f41e0008ae6a34f6608883.pdf. Accessed 5 Sept 2019

Quinn S (2017) Using small cities to understand the crowd behind OpenStreetMap. GeoJournal 82:455-473. https://doi.org/ 10.1007/s10708-015-9695-6

Radke J, Mu L (2000) Spatial decompositions, modeling and mapping service regions to predict access to social programs. Geogr Inf Sci 6(2):105-112. https://doi.org/10.1080/10824000009480538

Rimal B (2015) Urbanization and the decline of agricultural land in Pokhara sub-metropolitan city, Nepal. J Agric Sci 5(1):5465

Rimal B, Baral H, Stork N et al (2015) Growing city and rapid land use transition: Assessing multiple hazards and risks in the Pokhara Valley, Nepal. Land 4:957-978. https://doi.org/10.3390/land4040957 Accessed 25 Feb 2019

Roberts BH (2014) Managing systems of secondary cities: policy responses in international development. The Cities Alliance, Brussels

Rondinelli DA (1986) Metropolitan growth and secondary cities development policy. Habitat Int 10:263-271

Rusk D (2006) Annexation and the fiscal fate of cities. The brookings institute metropolitan policy program https://www.cdfa. net/cdfa/cdfaweb.nsf/ord/7724d67227fa261688257936005c9e13/\$file/20060810_fateofcities.pdf. Accessed 15 May 19

Stock R (1983) Distance and the utilization of health facilities in rural Nigeria. Soc Sci Med vol 17:563-570. https://doi.org/10. 1016/0277-9536(83)90298-8 Accessed 29 Mar 2019

Taras H (2005) Physical activity and student performance at school. J Sch Health 75:214-218. https://doi.org/10.1111/j.17461561.2005.00026 Accessed 10 Mar 2019

Tchouawou T (2015) Revisiting the sources of growth: enhancing the efficiency of the port of Douala. The World Bank. http:// www.worldbank.org/en/country/cameroon/publication/cameroon-economic-update-revisiting-the-sources-of-growthenhancing-the-efficiency-of-the-port-of-douala. Accessed 17 May 2019

The African Development Bank (2015) Population and housing census of Cameroon, Cameroon data portal. http://cameroon. opendataforafrica.org//PHCC2015/population-and-housing-census-of-cameroon-2015?tsld=1010290. Accessed 22 Aug 2019

The World Bank (2018) Douala urban mobility project. http://documents.worldbank.org/curated/en/793461558540522213/ pdf/Concept-Project-Information-Document-Integrated-Safeguards-Data-Sheet-Douala-Urban-Mobility-Project-P167795. pdf. Accessed 2 Sept 2019

The World Bank (2019) Poverty and equity data portal-Nepal. http://povertydata.worldbank.org/poverty/country/NPL. Accessed 5 Sept 2019

Thomas E, Serwicka I, Swinney P (2015) Urban demographics. Why people live where they do. Center for cities. https://doi. org/10.13140/RG.2.1.1053.8965 Accessed 15 Mar 2019

Twigg L (1990) Health based geographical information systems: their potential examined in the light of existing data sources. Soc Sci Med 30:143-155. https://doi.org/10.1016/0277-9536(90)90337-R

UN-DESA (2018) World urbanization prospects: the 2018 revision. https://population.un.org/wup/. Accessed 26 Feb 2019

UNICEF (2018) Maternal and newborn health disparities: Cameroon. https://data.unicef.org/wp-content/uploads/country profiles/Cameroon/Maternal\%20and\%20newborn\%20health\%20country\%20profiles/country\%20profile_CMR.pdf. Accessed 12 Sept 2019

United Nations Department of Economic and Social Affairs (2016) The world's cities in 2016. https://www.un-library.org/ population-and-demography/the-world-s-cities-in-2016_8519891f-en. Accessed 6 Mar 2019

University of Berkeley, Museum of Vertebrate Zoology and the International Rice Research Institute (2012) Global administrative areas (Boundaries). https://www.diva-gis.org/gdata. Accessed 8 June 2016

University of Waterloo Geospatial Centre (2012) Global administrative areas (GADM). https://uwaterloo.ca/library/geospatial/ collections/us-and-world-geospatial-data-resources/global-administrative-areas-gadm. Accessed 12 July 2016

Wang L (2018) Unequal spatial accessibility of integration-promoting resources and immigrant health: A mixed-methods approach. Appl Geogr 92:140-149. https://doi.org/10.1016/j.apgeog.2018.01.017 
Winters M, Teschke K, Grant M (2010) How far out of the way will we travel?: Built environment influences on route selection for bicycle and car travel. Transp Res Rec 2190:1-10. https://doi.org/10.3141/2190-01 Accessed 15 Mar 2019

World Food Programme (2017) Comprehensive food security and vulnerability analysis (CFSVA), Cameroon. https://reliefweb. int/report/cameroon/cameroon-comprehensive-food-security-and-vulnerability-analysis-cfsva-december-2017. Accessed 2 Sept 2019

World Health Organization (2019) What do we mean by availability, accessibility, acceptability and quality (AAAQ) of the health workforce? https:/www.who.int/workforcealliance/media/qa/04/en/. Accessed 26 Aug 2019

World Justice Project (2013) Cameroon healthcare access program. https:/worldjusticeproject.org/our-work/programs/ cameroon-healthcare-access-program. Accessed 2 Sept 2019

WorldPop (2015) School of geography and environmental science, University of Southampton. www.worldpop.org. Accessed 8 Feb 2019

Yeh GY-Y (1999) Urban planning and GIS. Geogr Inf Syst 2:877-888. Accessed 30 Jan 2019

Yengoh GT, Fogwe ZN, Armah FA (2017) Floods in the Douala metropolis, Cameroon: Attribution to changes in rainfall characteristics or planning failures? J Environ Plann Man 60:204-230. https://doi.org/10.1080/09640568.2016.1149048 Accessed 26 Feb 2019

Youssoufa MB, Somorin O, Sonwa D, Johnson NN, Locatelli B (2011) Forests and climate change adaptation policies in Cameroon. Mitig Adapt Strateg Glob Chang 16:369-385 Accessed 25 Mar 2019

\section{Publisher's Note}

Springer Nature remains neutral with regard to jurisdictional claims in published maps and institutional affiliations.

Submit your manuscript to a SpringerOpen ${ }^{\odot}$ journal and benefit from:

- Convenient online submission

- Rigorous peer review

- Open access: articles freely available online

High visibility within the field

- Retaining the copyright to your article

Submit your next manuscript at $\boldsymbol{\nabla}$ springeropen.com 